\title{
Nonlinear FE analysis of a full scale in situ test on a RC bridge by means of a 1D layered frame model
}

\author{
D. Ferreira, J. Bairán \& A. Marí \\ Universitat Politècnica de Catalunya, Spain
}

\begin{abstract}
Assessment, upgrading and strengthening of ageing civil infrastructure is a major task for Europe. The aim is to extend the life-time of existing concrete bridges without loss of safety. Nonlinear finite element analysis (NLFEA) can quantify the reserve capacity of existing structures and prevent premature dismantle; however, this technique is still seldom used in practice. 2D and 3D FE models, due to high time consumption and complexity, are barely applied at large scale. In this communication, a 1D layered frame model with force-interaction is used to simulate the experimental full scale test of a RC railway bridge in Örnsköldsvik, Sweden, failing in a combination of shear-bending-torsion. Available 2D and 3D NLFEA performed with commercial software are compared. Due to the computational efficiency and relative simplicity, the 1D layered frame model can be a reference for more sophisticated continuum models in preliminary assessment stages.
\end{abstract}

\section{INTRODUCTION}

Many ageing bridges are now facing issues of fulfilment of safety standards and decisions of dismantling or strengthening. Handling this problem is nowadays a strategic priority: the sustainable competitiveness of the construction sector has a tremendous impact in the proclaimed objectives of 'smart, sustainable and inclusive growth' of the Europe 2020 strategy (European Commission, 2010, European Commission, 2012). Europe has 500,000 railway bridges, $35 \%$ of which are over 100 years old and 1,000,000 roadway bridges with an average age of 50 years (MAINLINE, 2011). In all 27 countries of the European Union, the total expenditure in maintenance, repair and renewal was estimated at $€ 400$ billion in 2004 (COST-345, 2004). Due to the large sums involved, the financing of these activities needs to be put on a rational basis.

Here, nonlinear finite element analysis (NLFEA) can play a key role. In fact, determining the hidden capacity of these bridges through advanced predictive models, such as NLFEA, can extend their lifetime without loss of safety, representing huge economic and environmental savings. Although the development of NLFEA models for reinforced concrete (RC) structures started almost 40 years ago (FIB, 2008), these are still seldom used in practice and at true structural scale. These methods are almost exclusively used in academia and research by means of 2D and 3D FE models and its application is often limited to small/medium-scale laboratory specimens. This is because continuum models are too complex, time consuming, require fine $\mathrm{FE}$ meshes that can hardly be applied at the true structural scale of bridges.

A contribution to bridging this gap has been attained recently by enriching layered Timoshenko beam elements so as to include shear/bending interaction (Ferreira, 2013, Ferreira et al., 2013a). In this way, detailed 2D constitutive laws can be implemented in an analysis tool that is familiar to structural engineers and which allows the nonlinear analysis of large scale bridges in an efficient way. In fact, fibre beam models have been traditionally used for bending analysis, e.g. (Kang and Scordelis, 1980, Marí, 1984, Marí, 2000), and enlarging its formulation to consider force interaction is nowadays an important research trend. Examples of further models recently developed in this topic are (Bairán and Marí, 2006, Mohr et al., 2010, Navarro et al., 2007), differing on the level of complexity and applicability. Relevant state-of-the-art on this theme can be found in (Bairán and Marí, 2007, Ceresa et al., 2010)

A further drawback for the application of NLFEA at largest scale is that experimental tests on bridges, crucial to validate and compare computer calculations at the true structural scale, are very scarce. Recently, in the ambit of the European Project 'Sustainable Bridges' (SB, 2007), a continuous RC railway bridge in Örnsköldsvik, Sweden, was submitted to a loading in situ test until failure. The test 
involved a vast quantity and diversity of monitoring systems that provided valuable information for the validation of numerical models at the largest scale (SB-7.3, 2008). In this paper, the simulation of the experimental loading test of the bridge until failure by means of the 1D layered frame model is presented. A sensitivity analysis is performed with the 1D model by considering several approaches of simulation. In addition to comparing the numerical results with experimental data, 2D and 3D NLFEA performed with commercial software were also compared. Along with a reduction of calculation time, the few required variables are a further advantage in relation to $2 \mathrm{D}$ and $3 \mathrm{D}$ FE strategies to large scale structural application, where greater doubts on materials and geometry arise.

The presented 1D layered frame model is valuable for the assessment of existing bridges at preliminary stages, serving as a reference for more sophisticated models. Also, due to its numerical efficiency and robustness, it can contribute to broadening the scale of application of NLFEA to real structures and speed up the absorption of new computational tools by practitioners.

\section{NONLINEAR 1D LAYERED FRAME MODEL WITH FORCE INTERACTION}

The 1D layered frame model is a displacementbased fibre beam FE formulation for the nonlinear analysis of reinforced concrete (RC) and prestressed concrete (PC) frame structures. The general characteristics of the model are presented in Figure 1 for the different levels of analysis: structure, element, section, fibre and material.

Regarding the element level, the model is based on the Timoshenko 2D beam theory with the cross section discretized into fibres, the longitudinal reinforcement simulated by means of steel filaments and transversal reinforcement considered smeared.

At the sectional level, a shear-sensitive model accounts for the axial force-bending-shear interaction $(\mathrm{N}-\mathrm{M}-\mathrm{V})$ in all levels of material damage. This formulation is based on a hybrid (kinematic/force) approach and takes into account the multiaxial stresses generated in each fibre, as well as, the nonlinearities brought by cracking and the anisotropic behaviour of concrete. Here, the Bernoulli-Navier plane-section theory (kinematic-based assumption) that allows determining the longitudinal strain at each fibre as function of the generalized strains of the section is coupled with a constant shear stress constraint along the cross section (force-based assumption). The shear resistant fibres are considered to be located at the web of the cross-section and are under a 2D strain-stress state. In the flanges and cover, shear stresses are considered null. The criteria for the division of the cross-section into these two types of fi- bres are explained in (Ferreira et al., 2013a). Longitudinal steel filaments are only submitted to axial strains and stresses computed through the BernoulliNavier plane section theory. Torsion is accounted by means of an uncoupled constitutive law.

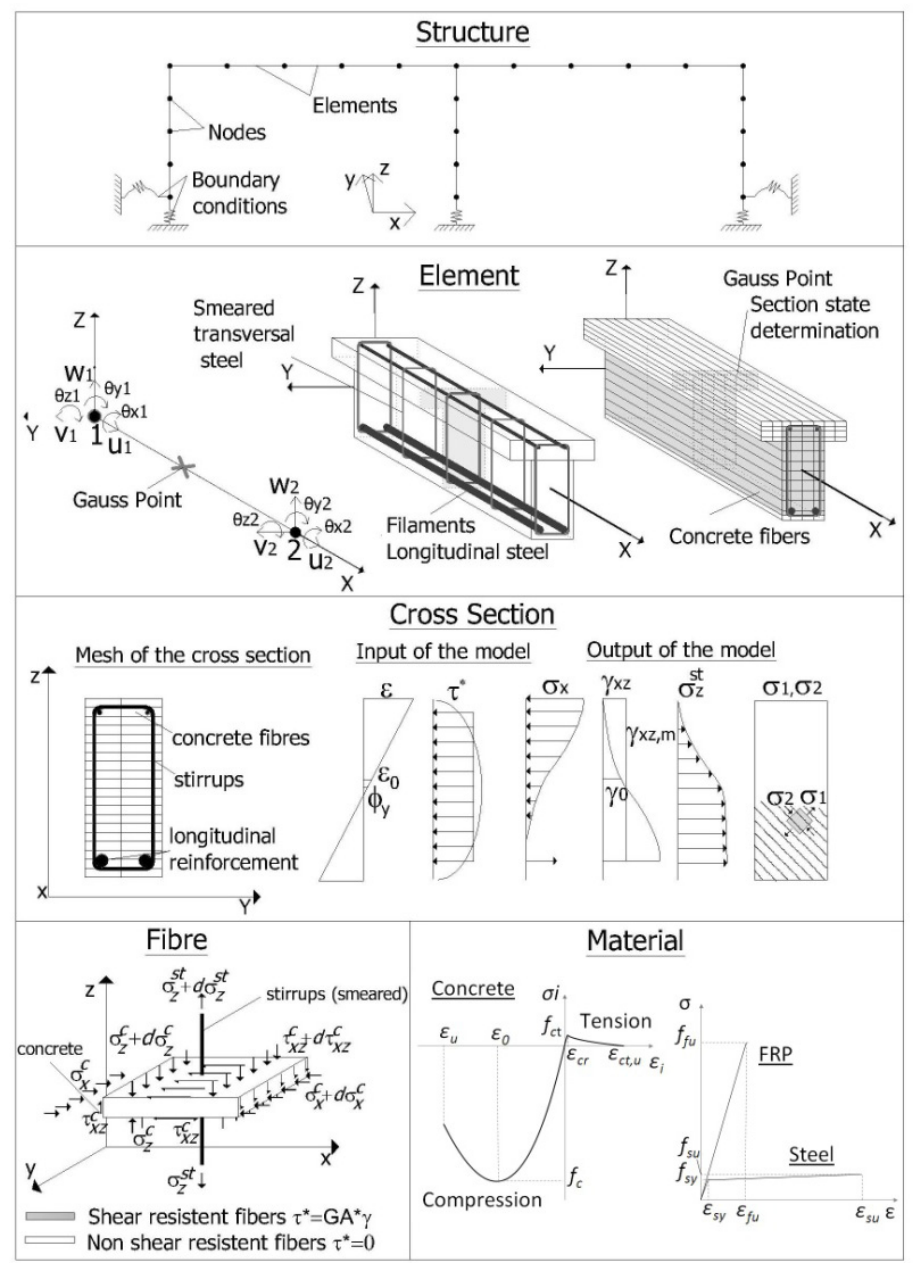

Figure 1. General characteristics of the 1D layered frame model with multiaxial force interaction

The strain-stress state in each fibre is represented in Figure 1 - Fibre. Transversal reinforcement is considered smeared through the volumetric ratio $\rho_{s t}$ and is submitted to axial stresses $\sigma_{z}^{s t}$. Compatibility requirements impose that the vertical strain $\varepsilon_{z}$ in concrete is equal to the strain in the transversal reinforcement. The computed shear stresses $\tau_{x z}$ must also equate the imposed shear stresses given by the fixed stress constraint $\tau^{*}$. By guaranteeing these two requirements, the state of the fibre is determined by computing the vertical axial strain $\varepsilon_{z}$ and shear strain $\gamma_{x z}$. This determination is not linear and an innermost iterative procedure within the fibre level is needed.

At the concrete material level, a smeared and rotating crack approach is considered. Cracked concrete is assumed as a homogeneous material with orthotropic behaviour and is simulated by means of average stress - average strain curves between the undamaged and cracked areas. A 2D nonlinear uniaxial - equivalent constitutive model is formulated in terms of average principal strains $\underline{\varepsilon}_{12}=\left[\begin{array}{ll}\varepsilon_{1} & \varepsilon_{2}\end{array}\right]^{\mathrm{T}}$ and 
stresses $\underline{\sigma}_{12}=\left[\sigma_{1} \sigma_{2}\right]^{\mathrm{T}}$. The Hognestad parabola is assumed for concrete in compression. Softening (Vecchio and Collins, 1986) and strength enhancement (Kupfer et al., 1969) factors are included for the respective states of compression-tension and biaxial compression. For concrete in tension a linear response is considered before cracking and the curve proposed by (Cervenka, 1985) is considered for the remaining stresses in the cracked stage. Longitudinal and transversal reinforcements are considered under 1D stress-strain states by means of a bilinear uniaxial constitutive equation with kinematic hardening. Fiber reinforced polymers (FRP) are modelled by a linear equation.

The nonlinear analysis is performed within a Newton-Raphson framework and continuation techniques such as Arc-length are available. The model is inserted in a phased and time-dependent framework allowing the simulation of segmental construction procedures and subsequent later changes, in which repair and strengthening interventions are included. Details on the formulation and validation of the model with shear critical laboratory benchmarks can be found in (Ferreira, 2013, Ferreira et al., 2013a, Ferreira et al., 2013c). The model was applied earlier to the assessment of a real bridge in (Ferreira et al., 2013b).

\section{LOADING TEST OF A RC BRIDGE IN ÖRNSKOLDSVIK, SWEDEN}

\subsection{Description}

A RC railway bridge in Örnsköldsvik, Sweden, was loaded until failure. The bridge was built in 1955 and putted out of service in 2005. The trough bridge is constituted by a 2-span $(12+12 \mathrm{~m})$ frame with a slight longitudinal curvature. Before dismantling, the bridge was tested in the ambit of the European Project 'Sustainable Bridges' involving a vast quantity and diversity of sensors (Figure 2a) (SB-7.3, 2008). Before testing, the beams of the bridge were strengthened longitudinally with fibre reinforced polymer (FRP) in order to attain a shear-sensitive failure mechanism instead of the well-investigated bending failure. Failure was due to a combination of lost of bond of the FRP and combined forces of shear, torsion and bending. All the information about this experimental test is available in the deliverables of the research project (SB, 2007). The geometry and reinforcement of the bridge are represented in Figures $2 \mathrm{~b}$ and $2 \mathrm{c}$. The original concrete quality corresponds to a compressive strength of $40 \mathrm{MPa}$ and reinforcement steel to nominal yield strength of 400 $\mathrm{MPa}$. Regarding material characterization, specimens of concrete and steel were taken from the bridge and tested in laboratory as described in (SB$7.3,2008)$.
Load was applied in load-control regime through steel tendons by two hydraulic jacks placed over a loading beam made of steel (Figure 2a). The loading beam was placed above the bridge beams at the middle of the second span (Figure $2 b$ ) in the direction transversal to the bridge axis. Steel tendons were anchored into the bedrock. The load was increased incrementally by $0.5 \mathrm{MN}$ with a rest time of 5 minutes. Failure occurred for a load level of 11.7 $\mathrm{MN}$ developing a main diagonal crack and due to a combination of shear-bending-torsion action driven by debonding of the FRP.
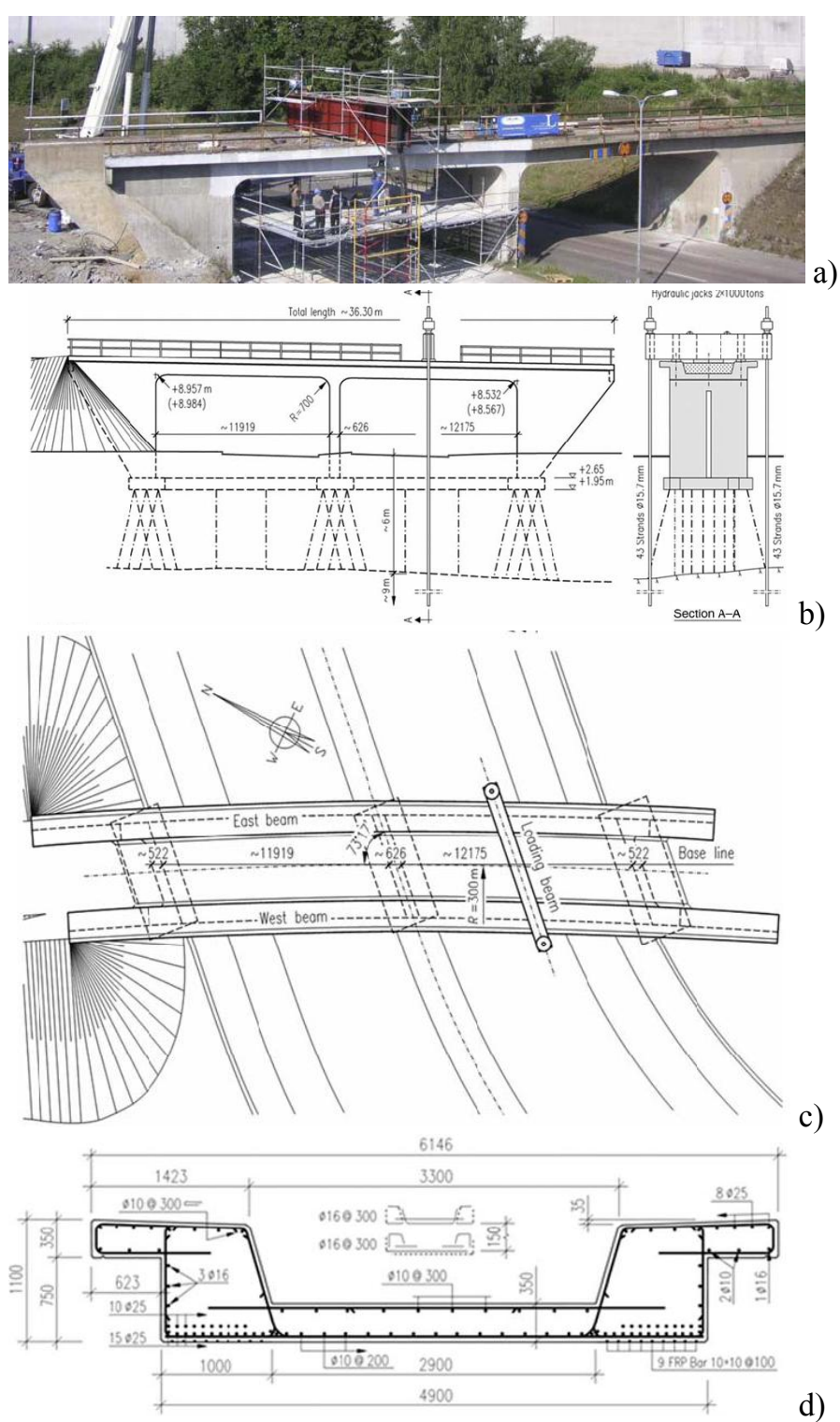

c)

Figure 2. Tested bridge in Örnsköldsvik, Sweden: a) photograph, b) elevation, c) plan and d) cross section and reinforcement including strengthening with CFRP. Adapted from (SB$7.3,2008)$.

The bridge was extensively monitored with high quantity and diversity of sensors (SB-7.3, 2008): electrical gauges to monitor strains in steel reinforcement, FRP and in concrete; optical laser displacement sensors and linear varying differential transducers for measurement of deflections; fibreoptic sensors for crack detection and; accelerometers 
for modal identification and damage detection. Strains and deflections were mainly measured under the point loads and close to the supports. A new methodology based on photographic strain monitoring was also applied providing very interesting information on the development of strain fields (Sas et al., 2012). All this data is valuable for comparison with numerical results in order to validate computational models at largest scale.

\subsection{Nonlinear FE analysis}

The entire bridge is simulated with the 1D layered frame model as presented in Figure 3. The FE mesh has 156 1D FEs and 123 nodes, involving the two beams and columns (East and West) and a slab connecting the beams (Figure 3a). The mesh is thinner in the area near the application of the load in order to get higher accuracy in the results. The cross sections are discretized into fibers of widths of $0.05 \mathrm{~m}$ for the beams and slab and $0.18 \mathrm{~m}$ for the columns (Figure $3 \mathrm{~b})$. The load is applied in the middle of the second span by two point-loads placed in the East and West beams. Given the slight inclination of the top flange of the beams (approx. 1.4 $4^{\circ}$, the point-load is decomposed into a horizontal and vertical component as represented in Figure $3 \mathrm{~b}$. The webs of the beams are considered shear resistant. The material properties considered in the models (Table 1) were based on the reports (SB-7.3, 2008) and also determined by the formulas of Eurocode 2 (EC2) (based on the experimental value of mean compression strength). The analyses include material and geometric nonlinearities. Load was applied incrementally in load steps of $50 \mathrm{kN}$ for each point-load until failure. The calculation takes around 30 minutes with a regular computer processing capacity.

Table 1. Material properties (in MPa)

\begin{tabular}{|c|c|c|c|}
\hline \multicolumn{2}{|c|}{ Concrete } & \multirow[b]{2}{*}{ Steel } & \multirow[b]{2}{*}{ FRP } \\
\hline $\begin{array}{l}\text { Mean exp. } \\
\text { values }\end{array}$ & $\begin{array}{c}\text { Mean values } \\
\text { EC2 }\left(\mathrm{f}_{\mathrm{c}, \mathrm{exp}}\right)\end{array}$ & & \\
\hline $\begin{array}{l}f_{c}=68.5 \\
f_{c t}=2.2 \\
E_{c}=25400\end{array}$ & $\begin{array}{l}f_{c}=68.5 \\
f_{c t}=5.02 \\
E_{c}=39200 \\
\varepsilon_{c u}=3.0 \mathrm{E}-3\end{array}$ & $\begin{array}{l}f_{s y}=441 \\
f_{s u}=706 \\
E_{s}=198000 \\
\varepsilon_{s u}=0.10\end{array}$ & $\begin{array}{l}f_{F u}=2002 \\
E_{F}=260000 \\
\varepsilon_{F u}=7.7 \mathrm{E}-3\end{array}$ \\
\hline
\end{tabular}

In order to perform sensibility analysis of the numerical model, several strategies of simulation were considered. The parameters analyzed were related with material properties, longitudinal configuration of the bridge, position of the bearing supports of the beams simulating the embankment, torsion model, debonding of FRP and importance of considering shear-bending interaction. As forcedisplacement curves give an idea of the overall response of the test, the most relevant analysis made are compared in Figure 4, where the experimental results are also included. The most important stages observed experimentally during loading are included in the graphic (in grey lines).
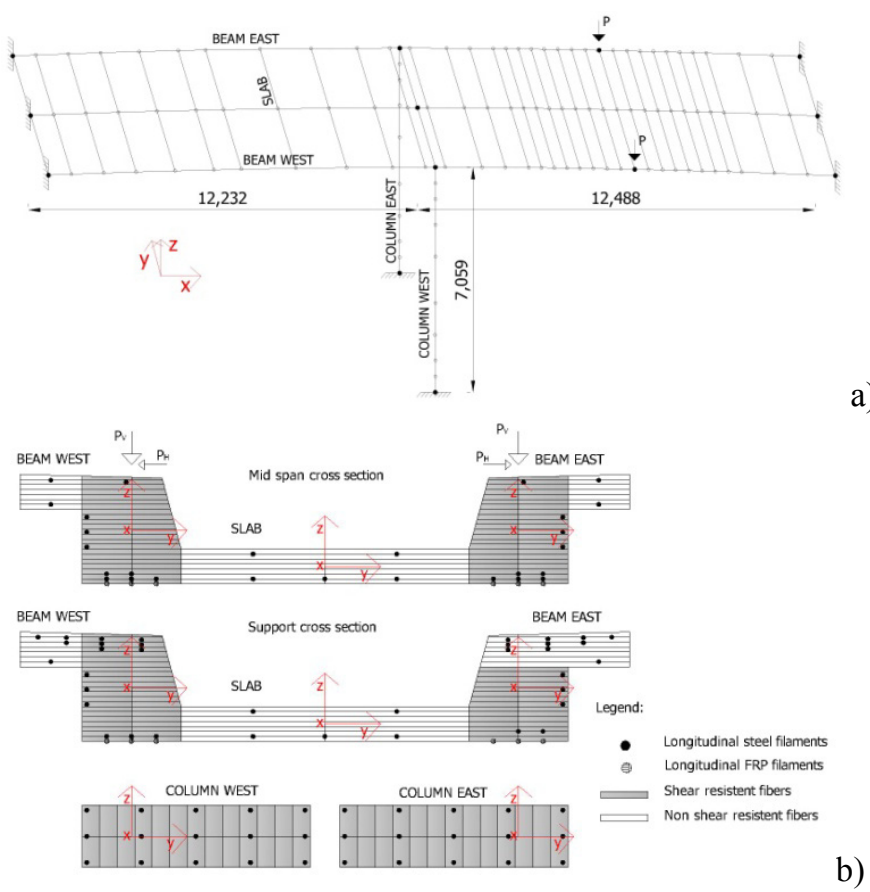

a)

b)

Figure 3. Simulation of the tested bridge by the 1D layered frame model: a) FE Mesh and b) cross section discretization.

In a first approximation, the curvature of the beam was not considered; it was simulated as straight. Also, the material properties of the model were taken as the mean values of the experimental tests on specimens of material taken from the bridge. The ultimate load (11.7 MN, around 2.8 times the predicted by the EC2 (SB-7.3, 2008)) was well captured by the 1D model at this first attempt (Model 1: $M-N$-V-straight-mat exp); no need for tuning of parameters was needed to acquire quality results of ultimate load. However, the stiffness of the bridge with this strategy was not well captured even at elastic stage, as the load-displacement curve did not fit the experimental. New material properties were considered in the model, based on the average concrete strength $f_{c}$ determined experimentally and making use of the expressions of EC2 to determine the other needed parameters for concrete (listed in Table 1). In this manner, elastic stiffness was well capture (Model 2: $N-M-V-$ straight). It is worth to mention that further NLFE models of the bridge used identical material properties as the ones used in this second trial (SB-7.3, 2008).

However, displacements were still underestimated by the model at higher load stages. To increase accuracy of the model, the slight longitudinal curvature of the bridge was accounted (Model 3: $\mathrm{N}$ $M-V$ - curve) resulting in higher deformations. Furthermore, studies on the influence of the tension stiffening law with lower stresses then default (Model 4: $N-M-V-$ curve - TS), the torsion constitutive model considering less stiff values than default (Model 5: $N-M-V-$ straight - torsion) and the posi- 
tions of the cantilever supports of the beams considering longer spans (Model 6: $N-M-V-$ curve - support) on the response were performed. Some enhancements on the displacement at higher loads were observed, however in some cases, convergence problems hinder to reach ultimate failure.

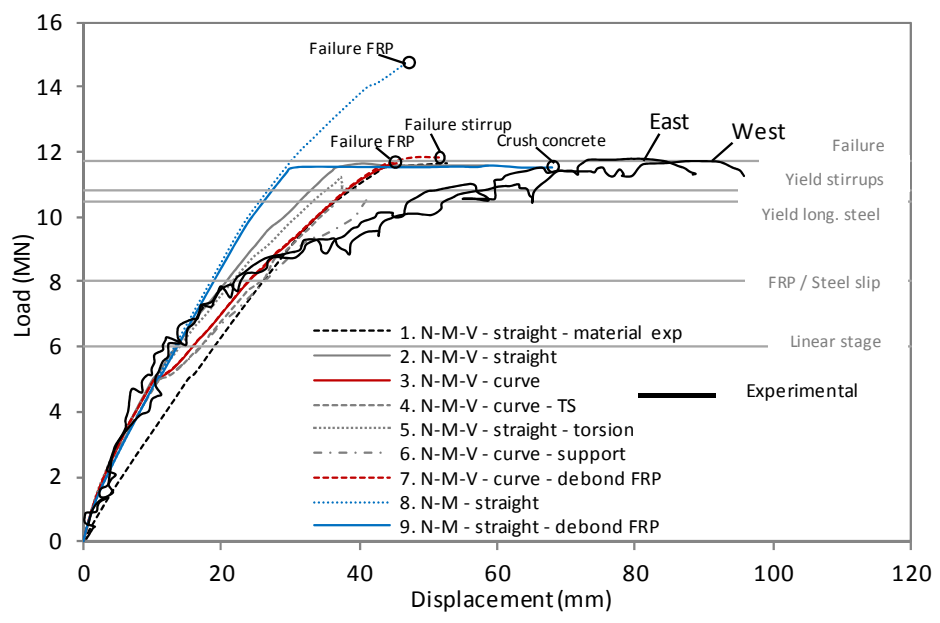

Figure 4. Load-displacement at mid span under load: experimental and numerical results with several modelling strategies.

Regarding the failure mechanism, the model originally predicted failure of FRP (Models 1, 2 and $3)$. Debonding mechanism is not considered in the formulation; hence, it is not able to capture the actual failure mode observed experimentally. At this stage, though, diagonal cracking and yielding of transversal reinforcement are predicted, showing damage due to combination of shear-bending (which will be discussed latter in this paper). In order to understand the importance of bonding loss of FRP in the failure mechanism of the bridge, further analysis were performed by taking off FRP in the load step immediately before failure (Model 7: $N-M-V-$ curve - debond FRP). The phased and time-dependent procedures available in the model allow these operations. Here, the analysis continues with yielded longitudinal and transversal steel reinforcement by increasing displacements without load gains until stirrups fail at approximately mid-shear span, as observed in field.

If shear is considered linear and nonlinear interaction is only due to bending, the analysis continues augmenting the load-carrying capacity until failure of FRP occurs for a higher load level (Model 8: $N-M$ - straight). If FRP is turned off near the failure load (Model 9: $N-M$ - straight - debond FRP), the model predicts bending failure through crushing of concrete and yielding of longitudinal reinforcement at this same load level. Due to the shear-sensitive failure mechanism, accounting for combined action of shear-bending forces in the model is of prime importance.

In resume, it can be observed that the ultimate load is fairly well captured by the model presenting little vulnerability to the parameters involved. There were some cases where convergence problems toke place and disable to continue the analysis until failure. However, in general, the computed loaddisplacement curves fit the experimental behavior until the start of bond slip between FRP and concrete. This load level was observed experimental and set as the moment when gauges in FRP and steel positioned at identical locations started to measure different values. At this stage, strains in FRP are higher than in steel. For this reason ultimate displacements at advanced damage state are underestimated by the model; also torsion effects and its interaction with other forces disregard by the model may contribute to this difference. Future work aims to enhance the numerical model to better account for these mechanisms.

Model $3(N-M-V-$ curve $)$ is the one that better represents the response of the bridge by using default parameters. Hence, only this model is considered in the following analysis of results.

\subsection{Comparison with $3 D$ FE models}

Simulations of this experimental test performed with commercial software and using NLFEA are available in (SB-7.3, 2008): a 2D FE model with ATENA and a 3D FE model with the Abaqus-based software Brigade. Load-displacement curves predicted by these models are represented in Figure 5, as well as, a representation of the FE meshes. In the case of the 2D FE model, 4-noded isoparametric quadrilateral elements were used. Two different analyses were performed: before and after the loading test. In the post-test analysis some material properties were changed and details on FRP and stirrups reinforcement were updated in relation to the pre-test analysis, (SB-7.3, 2008). A good agreement was achieved in terms of load-displacement curve, with an underestimation of the failure load. Regarding the 3D model, the bridge was simulated as a single solid part with nonlinear materials and discrete reinforcement by means of 152,460 elements and 164,003 nodes with a total number of variables of 511,317 (Puurula et al., 2013): shell elements for the steel beam, solid elements for the concrete bridge, 2-node linear 3D truss elements for reinforcement.

Further analysis were performed without accounting with the FRP, however, only the ones that considered the bridge strengthened are considered here. The load-displacement curve of the Model 3 ( $N-M-V$ - curve) is compared in Figure 5 with the results of these FE models of higher order and with the experimental data. It can be observed that the continuum simulations are very sensible to the parameters of the model and may present great discrepancy of results, even in terms of capturing the failure load. The higher quantity of parameters involved in these models, comparing with the 1D model, makes it 
more vulnerable uncertainties. The $3 \mathrm{D}$ model of (Puurula et al., 2013) fits well with the experimental results. These very good results were achieved with a great cost of detail and complexity of the model performed in a steadily manner by increasing the nonlinear materials step-by-step due to convergence problems (Puurula et al., 2013). Even tough, the model does not contemplate interface mechanism between concrete and FRP, so, it is not capable of capturing FRP debonding. Brigade model predicted tensile failure of the FRP; at this stage stirrups were yielded at the shear critical area.

The 1D layered frame model attained good results of ultimate load at first tentative and minor changes were included to increase the accuracy. This is the function of this simplified model; to give a perspective of the actual response of an existing structure without requiring a great computational effort, being valuable for the assessment at preliminary stages.
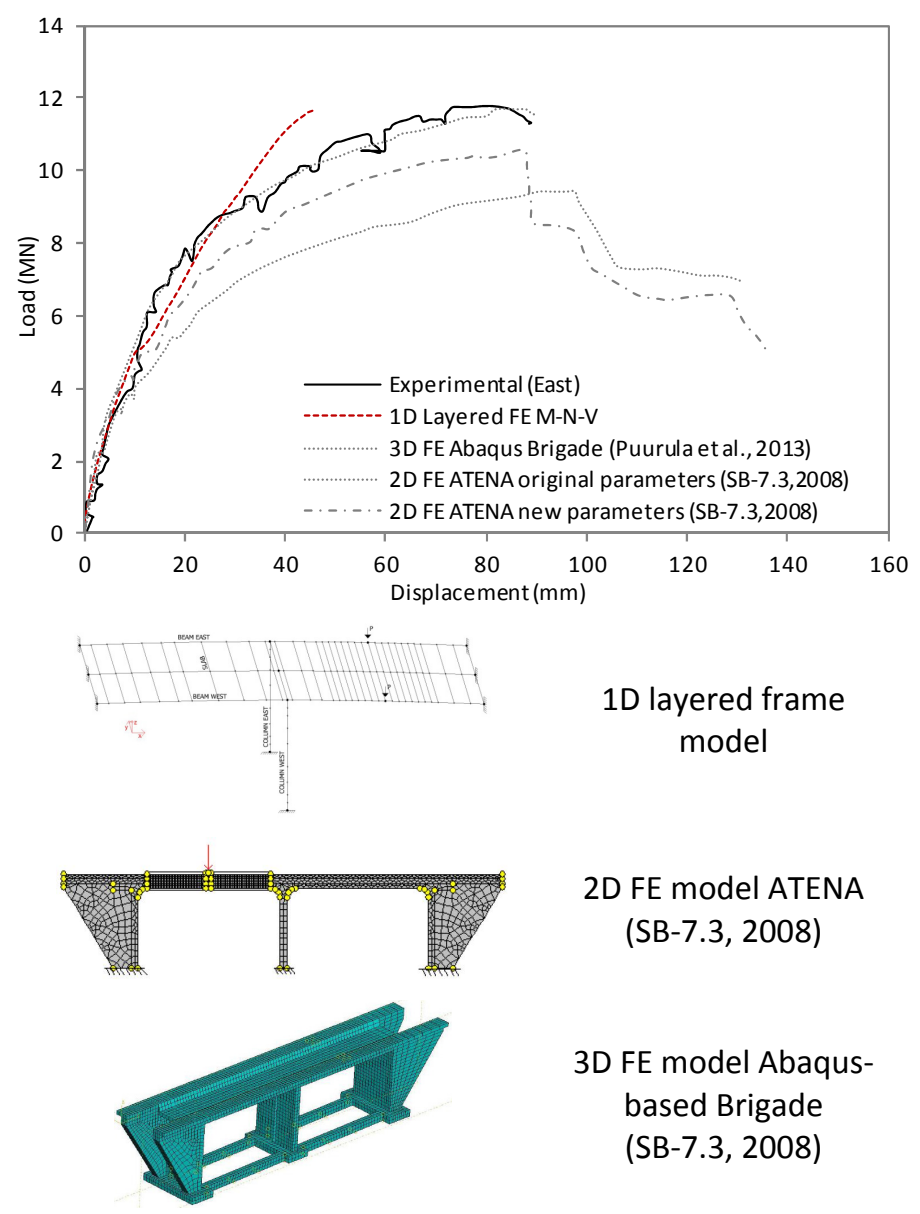

1D layered frame model

2D FE model ATENA

(SB-7.3, 2008)

3D FE model Abaqusbased Brigade (SB-7.3, 2008)

Figure 5. Load-displacement at mid span under load: experimental and numerical results with several orders of NLFEA.

\subsection{Strain fields and cracking}

Strains measured in concrete, steel and FRP at mid left span of the bridge are depicted in Figure 6 along with the predictions of the 1D layered model. The locations of the measurements within the cross section are also indicated in this Figure. Numerical results from the 2D and 3D NLFEA are not available in literature for compari- son. Both experimental results measured in the west and east beams (signed with $\mathrm{W}$ and $\mathrm{E}$ ) are represented. Numerical results refer to the East beam, as minimum differences exist between the two.

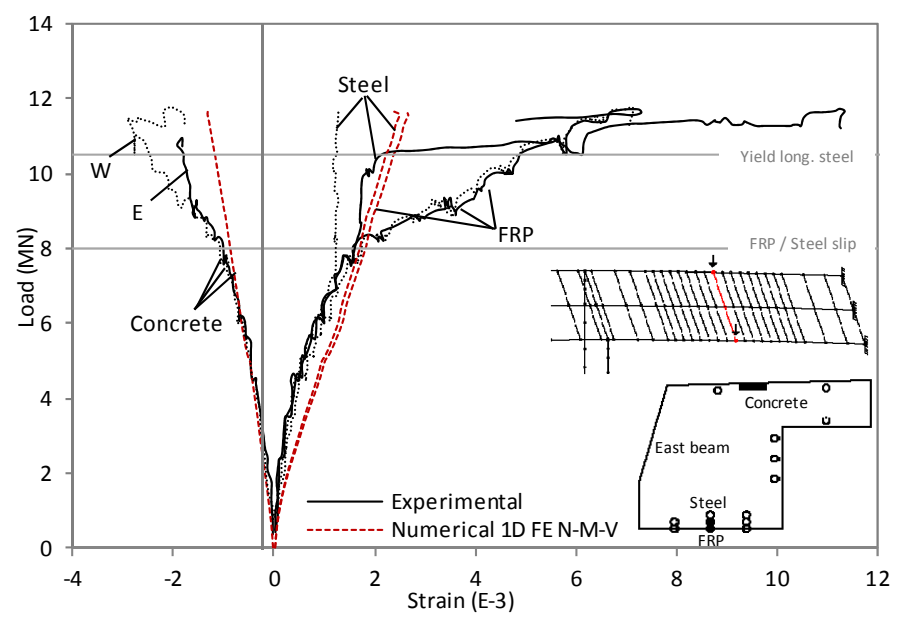

Figure 6. Load-strains in concrete, steel and FRP under load: experimental and numerical results.

Computed strains in concrete present a good fitting at early load stages, with less deformations predicted at higher levels of damage. Steel strains present an acceptable coherence with the experimental data, given the difficulty in this comparison due to the possibility of existence of cracks in the location of the sensors. By comparing the differences between the strains measured in steel and FRP it is perfectly noticeable the moment that bond-slip between FRP and concrete occurs. As this mechanism is not accounted in the model, at this load level, computed strains in FRP deviate significantly from the experimental.

The photographic monitoring method installed in field provided a graphical visualization of the strain field in the speckle area indicated in Figure 7a (Sas et al., 2012). Principal tensile strains measured at the load level of $10.8 \mathrm{MN}$ are represented in Figure $7 \mathrm{~b}$. At this load level, the cracks opened significantly. In the photometric measurements, strains vary in an interval of 300-25000 micro-strains. Peak values reflect the major cracks developed: values of 100005000-1000 micro-strains appear around the cracks. A rosette placed in the same area measured around 800 micro-strains (Sas et al., 2012). The principal strains computed by the numerical model are represented by the colour map in Figure 7c. The model assumes smeared cracking, hence, localize strains in the cracks are not accounted. Strains predicted by the model in this area, around 1200-18000 micro strains, present levels of magnitude in accordance with the measurements. The predicted crack pattern for this area is represented in Figure $7 d$, that was formed around $6 \mathrm{MN}$ of load. The inclination of the cracks agrees with the patterns marked by peak strains in the photographic monitoring. As the model 
assumes rotating cracking, the flow of principal tensile strains at load 10.8 MN (Figure 7c) does not fit with the cracking pattern (Figure $7 \mathrm{~d}$ ); tensile strains are flatter than cracks. The reason for this is that cracks form at a given load level and do not rotate; only new cracks appear with distinct inclinations. The numerical model, in contrast, assumes that cracks rotate continuously with loading.

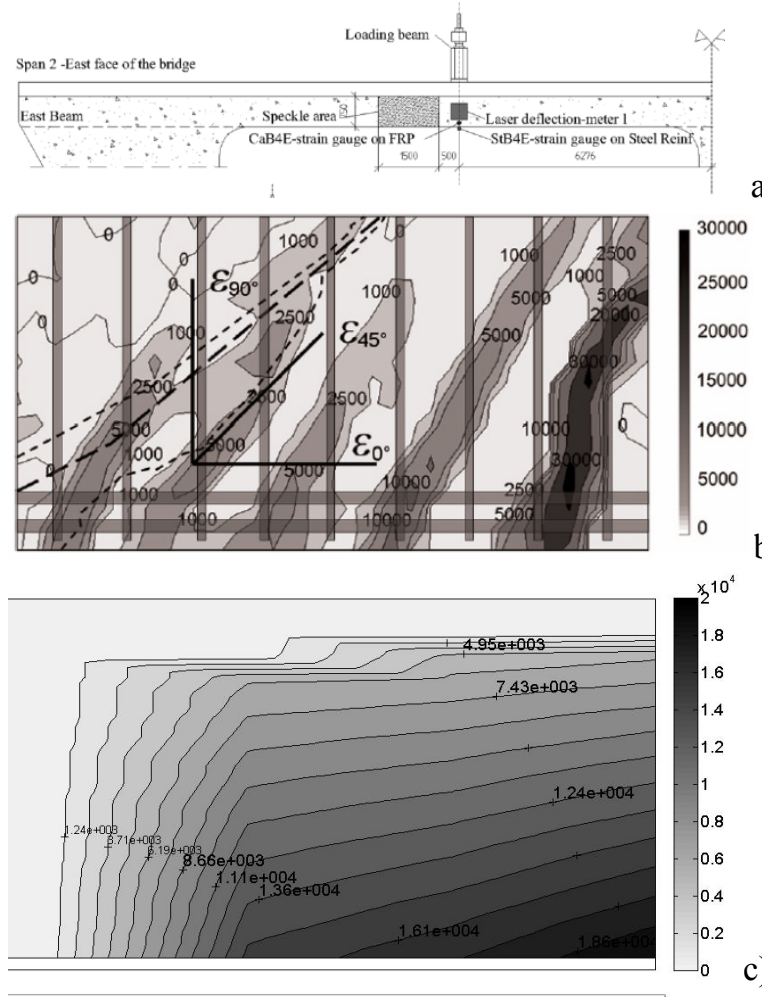

a)

c)

d)

Figure 7. Principal tensile strains in concrete: a) position of the speckle area, b) photographic measurements at $10.8 \mathrm{MN}$, c) computed strains at $10.8 \mathrm{MN}$ and d) predicted cracking by the model.

Pertaining to the failure mechanism, the model predicted failure of stirrups at shear span and yielding of longitudinal reinforcement at ultimate load stage, agreeing with experimental observations. Concerning the damage state at failure, the main diagonal crack in the bridge is represented in Figure 8a along with a detail of the failure of a stirrup. Cracking patterns at failure computed by the 1D model (Figure 8c) presented diagonal cracking, which is also in accordance with the predictions of the 2D model ATENA (Figure 8b) (SB-7.3, 2008). Stresses in stirrups at ultimate load given by the 1D model (Figure 8d) demonstrate the generalized yielding and the nearby failure of the transversal reinforcement at the right shear span.

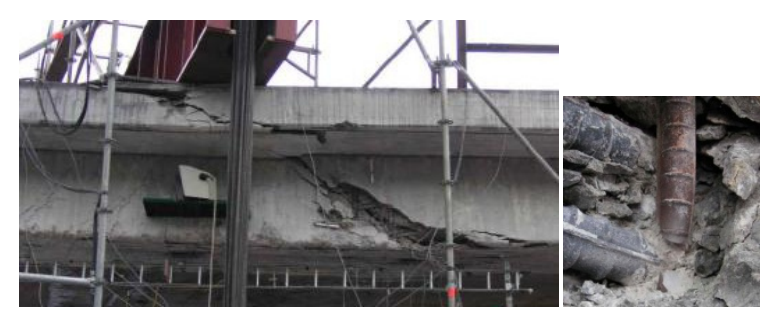

a)

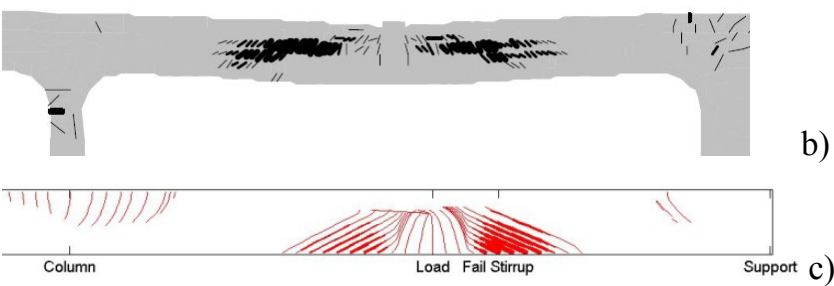

b)

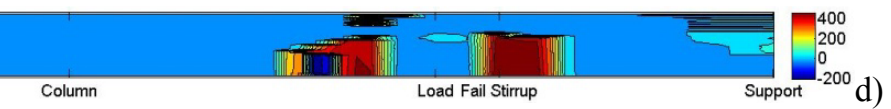

Figure 8. Damage at failure: a) observed (SB-7.3, 2008), b) cracking by 2D FE model ATENA (SB-7.3, 2008), c) cracking and $b)$ strains in stirrups by 1D layered model

\section{CONCLUSIONS}

The structural performance and load carrying capacity of aging concrete bridges is essential to ensure proper decisions related with the change of use, demolition or repair/retrofit measures and, in this manner, avoiding unnecessary, costly or inadequate interventions. NLFEA is a key tool to predict the structural response in an accurate and economical manner. However this technique is seldom used in practice. Robust and efficient models, with simpler input processes, more straightforward interpretation of the results and shorter computation times may contribute to shift this attitude. The 1D layered frame model with force interaction presented in this communication is an appealing alternative to $2 \mathrm{D}$ and 3D FEA for preliminary assessment of existing structures with the inherent advantages of simplicity and computational efficiency.

The model was used to simulate a loading test of a bridge until failure, the Örnsköldsvik bridge in Sweden. A sensitivity analysis was performed considering different strategies regarding variables such as: longitudinal configuration of the bridge, material parameters, bond loss of FRP, consideration of shear effects and force interaction, torsion model and position of the bearing supports of the beams. Results from 2D and 3D NLFEA performed with commercial software available in literature were compared with the 1D model. The 1D model captured failure load accurately at first trial, without tuning of parameters. Displacements at ultimate stages were underestimated by the 1D model due to disregarding bond-slip and torsion interaction with other forces. By comparing further numerical results with experimental data in terms strains and damage at fail- 
ure, an acceptable agreement was observed. Due to the shear-sensitive failure mechanism of the bridge, the consideration of force-interaction is essential to acquire quality results by means of 1D layered frame strategies.

Hence, the 1D layered frame model can be an adequate tool for preliminary assessment of existing bridges demanding strengthening, acting as a reference for more complex models. In this context, future research lines to enhance the model include a deeper study on the effects of torsion trough a paired beam mesh configuration; the consideration of bondslip mechanism and bond failure between FRP and concrete and; the linkage with a probabilistic framework.

\section{AKNOWLEDGEMENTS}

The present research has been carried out with the support of the project "Performance-based-design of partially prestressed concrete structures. Proposal of new design methodology, experimental verification and design criteria." (BIA2012-36848), financed by the Spanish Ministry of Economics and Competitiveness. The Postdoctoral Fellowship conceded by the Government of Catalonia (ref. 2013 PDJ 00022) to the first author is also gratefully acknowledged.

\section{REFERENCES}

BAIRÁN, J. \& MARÍ, A. (2006) Coupled model for the non-linear analysis of anisotropic sections subjected to general 3D loading. Part 1: Theoretical formulation. Computers \& Structures, 84, 2254-2263.

BAIRÁN, J. \& MARÍ, A. (2007) Shear-bendingtorsion interaction in structural concrete members: a nonlinear coupled sectional approach. Arch Comput Methods Eng, 14, 249278.

CERESA, P., PETRINI, L. \& PINHO, R. (2010) Flexure-shear fiber beam-column elements for modeling frame structures under seismic loading - State of the Art. Journal of Earthquake Engineering, 11, 46-88.

CERVENKA, V. (1985) Constitutive model for cracked reinforced concrete. ACI Journal, 82, 877-882.

COST-345 (2004) Procedures Required for the Assessment of Highway Structures - Final report. IN JORDAN R \& A, Z. (Eds.) European Commission - Directorate General Transport and Energy.

EUROPEAN COMMISSION (2010) EUROPE 2020. A strategy for smart, sustainable and inclusive growth. Communication from the commission. COM (2010) 2020 final. Brussels, 3.3.2010.
EUROPEAN COMMISSION (2012) Strategy for the sustainable competitiveness of the construction sector and its enterprises. Communication from the Commission to the European Parliament and Council. COM (2012) 413 final. Brussels, 31.7.2012.

FERREIRA, D. (2013) A model for the nonlinear, time-dependent and strengthening analysis of shear critical frame concrete structures. Departament D'Enginyeria de la Construcció. Barcelona, Universitat Politècnica de Catalunya. Escola Tècnica Superior d'Enginyers de Camins, Canals i Ports.

FERREIRA, D., BAIRÁN, J. M. \& MARÍ, A. (2013a) Numerical simulation of shearstrengthened RC beams. Engineering Structures, 46, 359-374.

FERREIRA, D., MARÍ, A. \& BAIRÁN, J. M. (2013b) Assessment of prestressed concrete bridge girders with low shear reinforcement by means of a non-linear filament frame model. Structure and Infrastructure Engineering, Article in Press.

FERREIRA, D., OLLER, E., MARÍ, A. \& BAIRÁN, J. M. (2013c) Numerical analysis of shear critical RC beams strengthened in shear with FRP sheets. Journal of Composites for Construction, 17.

FIB (2008) A Practitioner's Guide to ComputerBased Modelling of Structural Concrete Lausanne.

KANG, Y. \& SCORDELIS, A. (1980) Nonlinear analysis of prestressed concrete frames. Journal of Structural Division, 106, 445-462.

KUPFER, H., HILSDORF, H. K. \& RUSCH, H. (1969) Behavior of concrete under biaxial stresses. ACI Journal, 66, 656-666.

MAINLINE (2011) MAINtenance, renewal and Improvement of rail transport iNfrastructure

to reduce Economic and environmental impacts. IN EUROPEAN PROJECT, F.-S.-.-R.-. (Ed.

MARÍ, A. R. (1984) Nonlinear geometric, material and time dependent analysis of three dimensional reinforced and prestressed concrete frames. Structural Engineering and Structural Mechanics. Department of Civil Engineering. University of California. Berkeley, California.

MARÍ, A. R. B. (2000) Numerical simulation of the segmental construction of three dimensional concrete frames. Engineering Structures, 22, 585-596.

MOHR, S., BAIRÁN, J. \& MARÍ, A. R. (2010) A frame element model for the analysis of reinforced concrete structures under shear and bending. Engineering Structures, 32, 39363954.

NAVARRO, J. G., MIGUEL SOSA, P., FERNANDEZ PRADA, M. A. \& FILIPPOU, F. C. (2007) A 3D numerical model for reinforced and prestressed concrete elements subjected to combined axial, bending, shear and torsion loading. Engineering Structures, 29, 34043419 . 
PUURULA, A. M., ENOCHSSON, O., SAS, G., BLANKSVARD, T., OHLSSON, U., BERNSPANG, L., TALJSTEN, B. \& ELFGREN, L. (2013) Loading to failure and 3D nonlinear FE modelling of a strengthened RC bridge. Structure and Infrastructure Engineering, published online (in press).

SAS, G., BLANKSVARD, T., ENOCHSSON, O., TALJSTEN, B. \& ELFGREN, L. (2012) Photografic strain monitoring during fullscale failure testing of Ornskoldsvik bridge. Structural Health Monitoring, 11, 489-498.

SB-7.3 (2008) Field Test of a concrete bridge in Ornskoldsvik, Sweden. . IN ELFGREN L., ENOCHSSON O. \& H., T. (Eds.) Deriverable D 7.3, sustainable bridges - Assessment for future traffic demands and longer lives. Available from www.sustainablebridges.net.

SB (2007) Sustainable bridges - assessment for future traffic demands and longer lives. $A$ European Integrated Research Project during 2003-2008 within FP6. No TIP3-CT2003-001653. Available from www.sustainablebridges.net.

VECCHIO, F. J. \& COLLINS, M. P. (1986) The modified compession-fiel theory for reinforced concrete elements subjected to shear. ACI Journal, 83, 1357-1417. 